\title{
Influencing Factors and Scenario Forecasts of Carbon Emissions of the Chinese Power Industry: Based on a Generalized Divisia Index Model and Monte Carlo Simulation
}

\author{
Lin Zhu ${ }^{1}$, Lichun $\mathrm{He}^{2}$, Peipei Shang ${ }^{3}$, Yingchun Zhang ${ }^{4}$ and Xiaojun Ma ${ }^{1, *}$ \\ 1 School of Statistics, Dongbei University of Finance and Economics, Dalian 116025, China; \\ zhulinzl@outlook.com \\ 2 School of Public Administration, Dongbei University of Finance and Economics, Dalian 116025, China; \\ lichunhelch@outlook.com \\ 3 Editorial Department, Dongbei University of Finance and Economics, Dalian 116025, China; \\ peipeishangpps@outlook.com \\ 4 School of Economics, Qingdao University, Qingdao 266071, China; zhangyc@qdu.edu.cn \\ * Correspondence: maxiaojun@dufe.edu.cn; Tel.: +86-189-009-54292
}

Received: 18 August 2018; Accepted: 8 September 2018; Published: 11 September 2018

\begin{abstract}
The power industry is the industry with the most direct uses of fossil fuels in China and is one of China's main carbon industries. A comprehensive and accurate analysis of the impacts of carbon emissions by the power industry can reveal the potential for carbon emissions reductions in the power industry to achieve China's emissions reduction targets. The main contribution of this paper is the use of a Generalized Divisia Index Model for the first time to factorize the change of carbon emissions in China's power industry from 2000 to 2015, and gives full consideration to the influence of the economy, population, and energy consumption on the carbon emissions. At the same time, the Monte Carlo method is first used to predict the carbon emissions of the power industry from 2017 to 2030 under three different scenarios. The results show that the output scale is the most important factor leading to an increase in carbon emissions in China's power industry from 2000 to 2015, followed by the energy consumption scale and population size. Energy intensity levels have always promoted carbon emissions reduction in the power industry, where energy intensity and carbon intensity effects of energy consumption have great potential to mitigate carbon levels. By setting the main factors affecting carbon emissions in the future three scenarios, this paper predicts the carbon emissions of China's power industry from 2017 to 2030. Under the baseline scenario, the maximum probability range of the potential annual growth rate of carbon emissions by the power industry in China from 2017 to 2030 is 1.9-2.2\%. Under the low carbon scenario and technological breakthrough scenario, carbon emissions in China's power industry continue to decline from 2017 to 2030. The maximum probability range of the potential annual drop rate are measured at $1.6-2.1 \%$ and $1.9-2.4 \%$, respectively. The results of this study show that China's power industry still has great potential to reduce carbon emissions. In the future, the development of carbon emissions reduction in the power industry should focus on the innovation and development of energy saving and emissions reduction technology on the premise of further optimizing the energy structure and adhering to the low-carbon road.
\end{abstract}

Keywords: power industry; carbon emissions; Generalized Divisia Index; scenario forecast; Monte Carlo method 


\section{Introduction}

The increase of greenhouse gas emissions is the main reason for the sharp rise in global temperatures. Compared with the 19th century, the global temperature increased by $0.4-0.6{ }^{\circ} \mathrm{C}$ at the end of the 20th century. The United Nations Committee of Experts on Climate Change proposes that the threshold for global climate change is $2{ }^{\circ} \mathrm{C}$. If climate warming is not controlled, the global average temperature will rise by $4-6{ }^{\circ} \mathrm{C}$ in the 21 st century, which is $6-10$ times that of the 20 th century [1]. Global warming will bring a series of hazards, such as rising sea levels, melting glaciers, extreme weather, and so on, thus leading to a series of economic and political conflicts. By the summer of 2017, the area of Arctic sea ice had shrunk significantly [2], leaving only 4.1 million $\mathrm{km}^{2}$, which is $40 \%$ less than the average level in September 2000 (about 6.7 million $\mathrm{km}^{2}$ ) [3]. The rate of sea level rise in the recent 50 years is about $1.0-2.5 \mathrm{~mm}$ /year. With global warming, the sea level will continue to rise in the next $\approx 50-100$ years, and it will increase by about $12-50 \mathrm{~cm}$ by 2050 [4]. Climate warming has become the focus problem of the world's attention, and it is also a major challenge for humanity. Countries around the world have basically reached an agreement on climate change. On 4 November 2016, the Paris Agreement for global warming came into force. The goal is to control the global average temperature rise to within $2{ }^{\circ} \mathrm{C}$ by 2100 , compared with the pre-industrial period, and strive to control the temperature rise within $1.5^{\circ} \mathrm{C}$ [5]. Greenhouse gas emissions are an important cause of global warming. The greenhouse gases produced by humans are mainly carbon dioxide and other gases produced by the burning of fossil fuels. China is the world's largest carbon emitter. In 2015, China's carbon emissions reached 10.4 billion tons, accounting for $29 \%$ of global carbon emissions and exceeding the values of the United States and the 28 countries of the European Union [6]. As proposed in the "Global Carbon Budget 2016" [7] report, in 2016, China's carbon emissions reached 10.136 billion tons, accounting for $28 \%$ of the global total. According to the report, global carbon emissions were expected to increase by $2 \%$ in 2017 mainly because China's carbon emissions were expected to increase by $3.5 \%$ [7]. As the world's largest carbon emitter, China is actively shouldering its responsibility to reduce its emissions and has set a series of emission reduction targets. According to the "The Twelfth Five-Year Plan" period, China planned to pursue energy development efforts that involve accelerating the transformation of modes of energy development and controlling total energy consumption levels. "The Thirteenth Five-Year Plan" proposes a decline of energy intensity levels of 15\% [8]. In addition, the Chinese government has also proposed to substantially reduce its use of fossil fuels and to increase its clean energy consumption levels by 2030. The country's total energy consumption amounts to less than 6 billion tons of standard coal, and its unit gross domestic product (GDP) energy consumption level is in line with the global average. Carbon emissions generated per unit of GDP have been reduced by $60-65 \%$ from 2005, and the country's carbon emissions are set to peak by 2030. By 2050, the proportion of fossil fuel used will drop to below $50 \%$ and ideal energy-consumption levels will be achieved [9].

The production of electricity mainly relies on the use of thermal power, while the production of thermal power is mainly reliant on the use of coal. Nearly half of the coal that China develops each year is used to generate electricity, meaning that half of the carbon dioxide emitted by burning coal comes from the power industry. Furthermore, 70\% of China's energy comes from coal. According to the proportion of existing thermal power, at least one-quarter of the country's carbon emissions comes from the power industry [10]. As the basis of China's economic development, the power industry also directly relies on the sector that uses the most fossil fuels, and the proportion of its energy consumption in China's energy consumption has been rising. In 2015, the carbon emissions by the power industry accounted for about $32 \%$ of the total carbon emissions in the country, making it the largest source of greenhouse gas emissions in China. In 2015, fossil energy accounted for $74.2 \%$ of the energy consumption structure in the power industry, and low-carbon energy accounted for less than $30 \%$. Therefore, the adjustment of energy structure of the power industry has great carbon emission reduction potential. In 2015, the government proposed an ultra-low emissions action plan for coal-fired power plants: by 2020, coal-fired power generation will reduce carbon emissions by 180 million 
tons, and the total emissions of major pollutants in the power industry will be reduced by about 60\% [11]. In December 2017, China started to operate a nationwide carbon market explicitly targeting the power industry while taking the lead in launching a nationwide carbon emissions trading system and then gradually expanded its industrial scope, denoting the importance of energy conservation and emissions reduction in the power industry. Therefore, effective control of the carbon emissions by the power industry is central to achieving low-carbon development in China. In addition, the carbon emissions reduction targets proposed by the Chinese government will greatly accelerate the pace of energy structure optimization in China's power industry. Developing low-carbon power generation will become an important way to achieve carbon emissions reduction targets.

As an important carrier of a low-carbon economy, the development and use of low-carbon energy will fundamentally reduce human consumption of fossil energy and reduce greenhouse gas emissions. At present, low-carbon energy in the world mainly includes solar energy, wind energy, biomass energy, geothermal energy, nuclear energy, water energy, ocean energy, etc. With the progress of science and technology, the application of low-carbon energy gradually became widespread, and low-carbon energy generation technology has become a necessary choice to deal with the current energy crisis and environmental problems. China's current low-carbon energy generation technologies include wind power generation, solar photovoltaics power generation, biomass power generation, hydropower generation, and nuclear power generation. Among them, hydropower generation is the most widely used. China is rich in small hydropower resources, with an exploitable capacity of 87 million kW [12], ranking first in the world. Hydropower generation has a great development space. Nuclear power and wind power generation are also the main low-carbon energy technologies in China. For nuclear power, China has been actively developing nuclear power technology, and the advantages of nuclear power development in the third generation have been basically formed. For wind power generation, there are abundant wind resources in north China, northeast grassland, the northwest Gobi region, and southeast coastal areas. Wind power is stable in shallow coastal areas of eastern China, with the potential to build land and offshore wind farms. Solar photovoltaics is the fourth largest low carbon energy generation technology in China. China has a vast territory, and $70 \%$ of the land's annual average solar radiation accounts for more than $20 \%$ of the total time [13]. In addition, the western region is sparsely populated, which provides a very convenient condition for the collection and utilization of solar energy. A summary of China's major low carbon energy generation technologies is shown in Table 1.

According to Table 1, the proportion of China's low carbon energy generation is still lower than that of fossil energy, and in low-carbon energy, compared with traditional fossil energy power generation, the carbon emissions of solar photovoltaic power generation with the largest carbon emissions per unit of power generation is only $25.64 \%$ of coal power generation $\left(975.3 \mathrm{~g}-\mathrm{CO}_{2} / \mathrm{kWh}\right.$ ). Thus, low-carbon energy has great potential for reducing carbon emissions. 
Table 1. A summary of China's major low carbon energy generation technologies.

\begin{tabular}{|c|c|c|c|c|}
\hline $\begin{array}{l}\text { Low Carbon Energy } \\
\text { Generation Technology }\end{array}$ & Advantage & Disadvantage & $\begin{array}{c}\text { Application } \\
\text { (Data in 2017) [14] }\end{array}$ & $\begin{array}{l}\text { Carbon Emissions } \\
\left(\mathrm{g}-\mathrm{CO}_{2} / \mathrm{kWh}\right)[15,16]\end{array}$ \\
\hline Wind power generation & $\begin{array}{l}\text { High environmental benefits; } \\
\text { Renewable; } \\
\text { Short construction period; } \\
\text { Flexible application. }\end{array}$ & $\begin{array}{l}\text { Large area occupied; } \\
\text { Poor controllability; } \\
\text { High cost. }\end{array}$ & $\begin{array}{l}\text { Installed capacity is } 164 \text { million } \mathrm{kW} \text {. } \\
\text { The power generation capacity is } \\
305.7 \text { billion } \mathrm{kWh} \text {, } \\
\text { accounting for } 4.8 \% \text { of the total } \\
\text { power generation. }\end{array}$ & $\approx 9.7-123.7$ \\
\hline Hydropower generation & $\begin{array}{l}\text { High power generation efficiency; } \\
\text { Low power generation cost; } \\
\text { Base group starts fast; } \\
\text { Easy to adjust. }\end{array}$ & $\begin{array}{c}\text { Long construction period; } \\
\text { Small installed capacity; } \\
\text { High investment in infrastructure. }\end{array}$ & $\begin{array}{c}\text { Installed capacity is } 341 \text { million } \mathrm{kW} \text {. } \\
\text { The power generation capacity is } \\
1119.45 \text { billion } \mathrm{kWh} \text {, } \\
\text { accounting for } 18.6 \% \text { of the total } \\
\text { power generation. }\end{array}$ & $\approx 3.7-237$ \\
\hline $\begin{array}{l}\text { Solar photovoltaics } \\
\text { power generation }\end{array}$ & $\begin{array}{c}\text { No resource distribution } \\
\text { area restriction; } \\
\text { High energy quality; } \\
\text { Simple energy conversion process. }\end{array}$ & $\begin{array}{l}\text { Low energy density; } \\
\text { Large area occupied; } \\
\text { Vulnerable to climate. }\end{array}$ & $\begin{array}{c}\text { Installed capacity is } 130 \text { million } \mathrm{kW} \text {. } \\
\text { The power generation capacity is } \\
118.2 \text { billion } \mathrm{kWh} \text {, } \\
\text { accounting for } 1.8 \% \text { of the total } \\
\text { power generation. }\end{array}$ & $\approx 53.4-250$ \\
\hline Biomass power generation & $\begin{array}{c}\text { Low-sulfur; } \\
\text { High efficiency of investment } \\
\text { and utilization; } \\
\text { Strong production adjustment. }\end{array}$ & $\begin{array}{l}\text { High investment and power } \\
\text { generation costs; } \\
\text { Unstable fuel supply. }\end{array}$ & $\begin{array}{l}\text { Installed capacity is } 14.8 \text { million } \mathrm{kW} \text {. } \\
\text { The power generation capacity is } \\
79.5 \text { billion } \mathrm{kWh} \text {, accounting for } \\
1.2 \% \text { of the total power generation. }\end{array}$ & $\approx 35-178$ \\
\hline Nuclear power & $\begin{array}{c}\text { Huge energy; } \\
\text { No air pollution; } \\
\text { Easy to transport and store. }\end{array}$ & $\begin{array}{l}\text { Easy to produce radioactive waste; } \\
\text { Serious heat pollution; } \\
\text { High investment cost. }\end{array}$ & $\begin{array}{l}\text { Installed capacity is } 35.8 \text { million } \mathrm{kW} \text {. } \\
\text { The power generation capacity is } \\
247.469 \text { billion } \mathrm{kWh} \text {, accounting for } \\
3.94 \% \text { of the total power generation. }\end{array}$ & $\approx 10-130$ \\
\hline
\end{tabular}


To control the carbon emissions of the power industry more effectively, this paper decomposes the carbon emissions in the power industry, identifies the influencing factors of the carbon emissions in the power industry, and makes scenario analyses based on the future development trend of each influencing factor. At the same time, this paper fully considers the possibility of future technology development, and sets up the current scenario, low-carbon scenario, and technical breakthrough scenario, aiming to select the appropriate path of carbon emissions reduction for the power industry. Based on the existing research, this paper makes the following innovations in the decomposition of carbon emissions and scenario prediction in the power industry:

1. In applying the factor decomposition method, this study is the first to apply the Generalized Divisia Index Model (GDIM) to factor decomposition of carbon emissions by the power industry. The GDIM model can not only make up the factor dependence of the existing exponential decomposition model, but also considers the potential factors in the decomposition process and investigates the effect of multiple absolute factors and relative indices on carbon emissions. This paper uses the GDIM model to decompose the change of carbon emissions in China's power industry into absolute and relative value indices, which are not realized by other exponential decomposition methods. As the decomposition results reveal correlations among factors, no double-counting applies, which can make up for shortcomings of existing research methods while allowing a more complete and accurate analysis of the actual impacts of various factors on carbon emissions by the power industry.

2. In the selection of factor decomposition variables, this paper gives full consideration to the influence of the economy, population, energy consumption factors, and relative factors produced by absolute factors on the change of carbon emissions in the power industry. The paper examines the three absolute factors of the economy, population size, and energy consumption in measuring carbon emissions by the power industry and identifies relevant relative factors derived from three absolute factors, which make up the insufficiency of the analysis of carbon emissions from the electric power production and industrial angle. In addition, absolute factors and relative factors are taken into consideration, rendering our analysis of carbon emissions by the power industry more complete.

3. In the prediction of carbon emissions in the power industry, the first use of Monte Carlo simulation technology, and the uncertainty is considered in the scenario analysis. The Monte Carlo method is a dynamic simulation method that randomly applies and combines model variables on a probabilistic basis. The advantage of this method is that it can estimate the future change trend according to the assumption value of each use factor based on the relevant research. Because the uncertainty is considered, the pre-judgment results that are generated are more scientific and reasonable than those of other simulation methods. This paper combines China's development planning with a Monte Carlo simulation to forecast the situation of China's power industry, which can not only embody the inertial logic in a static scenario analysis, but also considers the uncertainty of the related influencing factors in the future evolution, such that the basic logic and scientific methods can be combined organically.

\section{Literature Review}

At present, academia has conducted extensive and in-depth research on carbon emissions. Quesada and Molina et al. [17] studied fifteen kinds of industrial carbon emissions in Spain and analyzed the gap between industrial carbon emissions and carbon emissions allocation rights. Quesada et al. [18] analyzed emissions and subsidies of the industries in different regions for the period between 2005 and 2009. Statistical analysis shows that there are significant differences between emissions and distribution in several regions. Mikayilov [19] investigated the relationship between the economic growth and $\mathrm{CO}_{2}$ emissions in Azerbaijan. Bollen [20] used the IMAGE 2 model to calculate regional carbon emissions and costs, and examined the emission reductions needed to allocate industrialized areas in a cost-effective manner. Carbon emission factors research is an important 
component of carbon emissions research. Remuzgo [21] analyzed the determinants of the global inequality distribution of carbon dioxide emissions across the regions considered by the International Energy Agency during the period 1990-2010. Zhu et al. [22] analyzed factor decomposition of carbon emissions generated in China from 1980 to 2007 and concluded that the output effect makes the greatest positive contribution to carbon emissions, and that the energy intensity effect makes the strongest negative contribution to carbon emissions. Xia et al. [23] considered the energy-related carbon emissions in Zhejiang Province from 2000 to 2014, and used Logarithmic Mean Divisia Index (LMDI) to factorize energy carbon emissions of Zhejiang Province. Kopidou [24] divided the study period into two sub-periods, 2000-2008 and 2008-2011, and decomposition of the carbon emissions of the industrial sectors of Greece, Italy, Spain, and Portugal to investigate how changes in the production and consumption of industrial products during the period 2000-2011 affected the industrial carbon emissions of the four southern European countries. Mahony [25] used the LMDI method to decompose the factors of Ireland's carbon emissions changes from 1990 to 2010 and studied the driving forces of carbon emissions. Wang et al. [26] employed the LMDI model to divide China's carbon emissions for 1995-2007 into 11 drivers and to study them. Wang and He [27] conducted a factor decomposition of China's carbon emissions for 1990 to 2007 using the LMDI factorization method and concluded that the economic growth and energy intensity effects, respectively, were the main factors that contributed to an increase and decrease in carbon emissions. Population and structural effects are not significantly affected. Du et al. [28], based on provincial panel data, studied the influence factors and potential emission reductions of China's carbon emissions from 1995 to 2009. Dong [29] used the LMDI model to categorize changes in China's carbon emissions increment and used the co-integration method to establish a co-integration relationship between each variable and carbon emissions. Based on the equation developed, carbon emissions were estimated via a Monte Carlo simulation.

Research on the carbon emissions by the power industry represents another important area of research. H. Ali et al. [30] used an Energy PLAN optimization model to assess the impact of Singapore's various strategies in the electricity generation sector on $\mathrm{CO}_{2}$ emissions from Singapore's electricity generation sector through to 2020. A comparison of a business-as-usual (BAU) scenario in 2020 (BAU 2020), 2020 target emissions reduction trajectory, and three emissions reduction alternative policy scenarios (denoted APS-I, APS-II, and APS-III) was carried out. Sun et al. [31] applied the Stochastic Impacts by Regression on Population, Affluence and Technology (STIRPAT) model to analyze the influencing factors of carbon emissions in the power industry. Wu and Peng [32] constructed the Long-Range Energy Alternatives Planning (LEAP) model to simulate China's national power needs in six scenarios and estimated carbon emissions and carbon intensity by 2030. Cai et al. [33] used a long-term alternative energy planning system to identify three scenarios for the future development of carbon emissions generated by China's power industry. The potential for carbon emissions reduction in the power industry was analyzed through a comparison of different scenarios, and the costs of key measures were quantified. Ari and Koksal [34] studied the carbon emissions from Turkey's electricity production and developed four scenarios based on different fuel mixtures. The results from these scenarios show that if the proportion of fossil energy inputs is reduced, carbon emissions from electricity production will be significantly reduced. Hou and Tan [35] used a logarithmic average weight method to divide the carbon emissions by the power industry into income, power production intensity, electricity production structure, population, and power generation coal consumption effects. For a typical period, carbon emissions factors were individually analyzed. Steenhof and Weber [36] developed a decomposition model for the Canadian electricity industry to assess the effects of various factors, particularly climate and energy policies, on emissions from 1990-2008, which affect greenhouse gas emissions in the sector. Based on the mechanism of carbon emissions in the power system, Chen et al. [37] analyzed carbon emissions results and the influencing factors of carbon emissions. The authors also established means of carbon emission structure identification and evaluation, and a way to estimate contributions of low levels of carbonization based on carbon emission structures was proposed and verified. Huo et al. [38] used LMDI decomposition methods to determine the carbon 
emissions by the power industry from 1991 to 2010 and analyzed the impacts of changes in plant electricity consumption, power generation structures, power generation coal consumption, and line loss on changes in carbon emissions generated by the power industry. A decrease in coal consumption levels is the main positive effect of carbon emission reduction. A short-term change in carbon emission intensity levels is mainly affected by the power generation structure used. A summary of research methods on carbon emissions generated by the power sector is given in Table 2 .

While prior studies have made substantial contributions to the understanding of carbon emissions by the power industry in China, there are still some deficiencies:

1. Regarding research methods, at present, the exponential decomposition method used in power industry factor decomposition is based on a Kaya identity. Kaya identity is determined by multiplying factors such that they are interdependent in form, and thus, decomposition results are affected by the factors selected. When the same target variable is decomposed, the selection of different factors will lead to contradictory conclusions. In addition, the exponential decomposition method used in the prior studies can only be used to analyze the impacts of a change in the absolute number of factors, and it cannot take other related absolute and implicit factors into account, rendering the analysis unilateral.

2. On the selection of research factors, the factor selected for the factor decomposition of the power industry presents a certain degree of one-sidedness. In the literature, two forms of factor selection are mainly used when factoring the power industry: (1) The first approach involves considering the impact of a single factor or policy on carbon emissions by the power industry, such that while research elements or policies can be studied through an accurate and in-depth analysis, the potential of carbon emissions by the power industry cannot be explored. (2) From an industrial point of view, they only consider the impact of production-side factors on carbon emissions by the power industry while neglecting the impact of output scales and population sizes, thus producing incomplete research results.

3. Regarding carbon emissions projections, most scenario analyses of various factors apply a fixed rate of change. In fact, the future development of various factors is largely uncertain and the potential rate of change should fall within a range of values. Using a fixed rate of change for forecasting can generate large deviations in forecasted results from future developments.

In this paper, the factor decomposition and scenario analysis are fully combined to avoid the singleness of only the factor decomposition or the integrated scenario analysis. By setting the changing range of the main influencing factors in different situations in the future, a Monte Carlo simulation is used to obtain the average annual conversion rate of carbon emissions from 2017 to 2030 in China's power industry in different scenarios. The shortcomings of the existing research are alleviated.

The article's structure is as follows: The third part constructs a model for the decomposition of carbon emissions in the power industry and its future scenario prediction. The fourth section decomposes factors that influence carbon emissions by the power industry and predicts changes in carbon emissions that will occur in the power industry from 2017-2030 via the Monte Carlo method. The fifth section contrasts the research results of this article with those of existing research, expounds on the significance of this article, and puts forward shortcomings of this article and avenues for improvement. The sixth section presents conclusions and policy recommendations. 
Table 2. Prior research on the carbon emissions by the power industry.

\begin{tabular}{|c|c|c|c|c|}
\hline Author & Research Methods & Research Approach & Research Conclusions & Research Limitations \\
\hline Shrestha et al. [39] & LMDI & $\begin{array}{l}\text { This paper analyzes the carbon emissions of the } \\
\text { power sector in } 15 \text { countries in Asia and the Pacific } \\
\text { using the LMDI model from the perspectives of } \\
\text { changes in economic output, electricity intensity of } \\
\text { the economy, fuel intensity of power generation, } \\
\text { and power generation structure. }\end{array}$ & $\begin{array}{l}\text { The increasing electricity intensity of the } \\
\text { economy was the main factor in Bangladesh, } \\
\text { Indonesia, and Philippines. Structural changes } \\
\text { in power generation were found to be the main } \\
\text { contributor to changes in the } \mathrm{CO}_{2} \text { emissions in } \\
\text { the case of Sri Lanka and New Zealand. } \\
\text { Economic growth was the dominant factor } \\
\text { behind the increase in } \mathrm{CO}_{2} \text { emissions in the } \\
\text { other countries. }\end{array}$ & $\begin{array}{l}\text { This paper uses the LMDI model to define each } \\
\text { contributing factor as interdependent, and the } \\
\text { results are found to be dependent on the choice } \\
\text { of factors. Thus, different forms of factor } \\
\text { decomposition may lead to the opposite } \\
\text { conclusion, and potential impacts of the } \\
\text { absolute quantity factor selected cannot } \\
\text { be determined. }\end{array}$ \\
\hline Malla et al. [40] & LMDI & $\begin{array}{l}\text { This paper uses the LMDI of complete } \\
\text { decomposition to examine the role of three factors } \\
\text { (electricity production, electricity generation } \\
\text { structure and energy intensity of electricity } \\
\text { generation) affecting the evolution of } \mathrm{CO}_{2} \\
\text { emissions from electricity generation in seven } \\
\text { Asia-Pacific and North American countries. }\end{array}$ & $\begin{array}{l}\text { The production effect is the main factor of } \mathrm{CO}_{2} \\
\text { emissions increase during } 1990-2005 \text {, and the } \\
\text { energy intensity effect is the main factor to } \\
\text { reduce the } \mathrm{CO}_{2} \text { emissions. In 2005-2030, } \\
\text { the structure effect of power generation plays a } \\
\text { role in reducing carbon emissions. The impact } \\
\text { of the factors varies by country. }\end{array}$ & $\begin{array}{l}\text { This paper mainly analyzes carbon emissions } \\
\text { by the power industry starting with the } \\
\text { production of electric power enterprises, but i } \\
\text { does not consider relevant factors such as } \\
\text { economic growth or population size with } \\
\text { one-sidedness. } \\
\text { The LMDI model presents limitations. }\end{array}$ \\
\hline Zhang et al. [41] & $\begin{array}{l}\text { Meta-frontier non-radial } \\
\text { directional distance function }\end{array}$ & $\begin{array}{l}\text { After considering the non-uniformity, non-radial } \\
\text { relaxation, and unwanted output of the power } \\
\text { generation group, this paper estimates the changes } \\
\text { in the energy use and } \mathrm{CO}_{2} \text { emissions of the Korean } \\
\text { power industry under different power } \\
\text { generation assumptions. }\end{array}$ & $\begin{array}{l}\text { The coal-fired power plant's total factor energy } \\
\text { efficiency and carbon dioxide emissions } \\
\text { performance is higher than the fuel power } \\
\text { plant, under the technical assumptions, } \\
\text { the technical difference of coal-fired power } \\
\text { plants is smaller than the fuel power plant. }\end{array}$ & $\begin{array}{l}\text { N. Zhang et al. only consider the single } \\
\text { factor's impact on the carbon emissions in the } \\
\text { power industry. Although it can well quantify } \\
\text { the carbon emissions reduction potential } \\
\text { brought by technology, it cannot grasp the } \\
\text { carbon emissions of the power industry as a } \\
\text { whole situation. }\end{array}$ \\
\hline Hu et al. [42] & LMDI & $\begin{array}{l}\text { This paper uses the LMDI exponential } \\
\text { decomposition method to examine the effects of } \\
\text { China's differential pricing policy on carbon } \\
\text { emissions by the power industry. Compare the } \\
\text { effectiveness of different pricing policies in } \\
\text { different industries. }\end{array}$ & $\begin{array}{l}\text { Electricity consumption in China's } \\
\text { energy-intensive industries is still growing. } \\
\text { Output effects make the largest contributions } \\
\text { to carbon reduction outcomes while intensity } \\
\text { effects represent the most adverse inverse } \\
\text { factor. Policies have different impacts on } \\
\text { different industries. }\end{array}$ & $\begin{array}{l}\text { J. Hu et al. take the difference pricing policy as } \\
\text { a starting point and only consider the potentia } \\
\text { of carbon emissions by the power industry } \\
\text { based on the policy of differential electricity } \\
\text { prices. The authors do not explore the potentia } \\
\text { of carbon emissions by the power industry. }\end{array}$ \\
\hline Özer et al. [43] & LEAP model & $\begin{array}{l}\text { This paper comprehensively considers the various } \\
\text { policies of Turkey and analyzes the carbon } \\
\text { emission reduction in Turkey's power sector based } \\
\text { on the scenario analysis of the Long-Range Energy } \\
\text { Alternatives Planning system (LEAP) model. }\end{array}$ & $\begin{array}{l}\text { Carbon dioxide }\left(\mathrm{CO}_{2}\right) \text { emissions will rise } \\
\text { significantly under the baseline scenario. In the } \\
\text { mitigation scenario, electricity-related } \mathrm{CO}_{2} \\
\text { emissions grew by } 5.8 \% \text { annually between } \\
2006 \text { and } 2030 \text {, while electricity output grew at } \\
\text { an average of } 6.6 \% \text { per annum in this period. }\end{array}$ & $\begin{array}{l}\text { Scenario analysis does not consider the degree } \\
\text { of impact of various factors affecting the } \\
\text { carbon emissions of the power sector, } \\
\text { which may lead to an increase in the bias of } \\
\text { future scenario estimates. }\end{array}$ \\
\hline Liu et al. [44] & $\begin{array}{l}\text { Multivariable linear regression } \\
\text { (MLR) model }\end{array}$ & $\begin{array}{l}\text { Taking Chongqing as an example, this paper } \\
\text { applies a multivariate linear analysis of factors } \\
\text { (e.g., industrial structure optimization and power } \\
\text { supply structure optimization) to design three } \\
\text { scenarios to examine the potential for carbon } \\
\text { emissions reduction in the power industry. }\end{array}$ & $\begin{array}{l}\text { Optimization of industrial structures and } \\
\text { promotion of emissions reduction technologies } \\
\text { have considerable effects on carbon emissions } \\
\text { reduction outcomes. Hydropower resources } \\
\text { will limit the power structure optimization of } \\
\text { carbon emissions reduction potential. }\end{array}$ & $\begin{array}{l}\text { This paper uses multiple linear analysis to } \\
\text { predict carbon emissions that will be generated } \\
\text { by the power industry in the future. As the } \\
\text { study does not consider various factors or } \\
\text { uncertainties related to future changes, } \\
\text { the results of the analysis are limited. }\end{array}$ \\
\hline
\end{tabular}




\section{Methods}

\subsection{Electricity Industry Carbon Emissions Calculations}

This paper refers to the "Intergovernmental Panel on Climate Change (IPCC) 2006" [45] published carbon emissions calculation method to estimate carbon emissions generated by China's power industry from the perspective of fossil fuel consumption. The following formula is used (1):

$$
C=\sum_{i=1}^{8} E_{i} \times C V_{i} \times C C F_{i} \times C O F_{i} \times(44 / 12)
$$

In Equation (1), $C$ represents carbon emissions by the power industry in $10^{4}$ tons; $i$ denotes the type of energy use. According to energy distinctions outlined by the IPCC, this paper examines eight energy sources (raw coal, coke, crude oil, gasoline, kerosene, diesel oil, fuel oil, and natural gas). $E_{i}$ is consumption of the $i$ th energy source, and the unit is $10^{4}$ tons of Standard Coal Equivalent (SCE). $C V_{i}$ is the low calorific value of the $i$ th energy source in $\mathrm{kJ} / \mathrm{kg}$ or $\mathrm{kJ} / \mathrm{m}^{3}, C C F_{i}$ is the carbon content of the $i$ th energy source in units of $\mathrm{kg} / 10^{6} \mathrm{~kJ}, C O F_{i}$ is the carbon oxidation rate of the $i$ th energy source, and $44 / 12$ is the molecular weight ratio of carbon dioxide to carbon.

In calculating carbon emissions generated by China's power industry, the energy consumption data used were drawn from the "China Energy Statistical Yearbook"(2001-2016) [46]; lower heating value, carbon content levels, and carbon oxidation rates for various energy sources were sourced from the "IPCC Guidelines for National Greenhouse Gas Inventories" [45].

\subsection{Model Construction for the Decomposition of Carbon Emission Factors by the Power Industry}

In this paper, GDIM is used to decompose carbon emissions by the power industry. The model establishes a multi-dimensional factorization model by transforming a Kaya identity that can reveal causes of carbon emission changes. We create Equations (2)-(4) based on the GDIM model

$$
\begin{gathered}
C=G \times(C / G)=E \times(C / E)=P \times(C / P) \\
E / G=(C / G) /(C / E) \\
(G / P)=(C / P) /(C / G)
\end{gathered}
$$

In Equations (2)-(4), $C$ denotes carbon emissions, $G$ denotes added value, $E$ denotes total energy consumption, $P$ denotes total population, $G / P$ denotes GDP per capita, $C / P$ denotes per capita carbon emissions, $C / G$ denotes output carbon intensity, $C / E$ denotes energy consumption carbon intensity, and $E / G$ denotes energy intensity.

Equations (2)-(4) are transformed to obtain Equations (5)-(9):

$$
\begin{gathered}
C=G \times(C / G) \\
G \times(C / G)-E \times(C / E)=0 \\
G \times(C / G)-P \times(C / P)=0 \\
G-P \times(G / P)=0 \\
E-G \times(E / G)=0
\end{gathered}
$$

Function $C(X)$ denotes the contribution of factor $X$ to changes in carbon emissions. According to Equations (5)-(9), we establish a Jacobian matrix $\Phi_{X}$ composed of various factors, as given in Equation (10): 


$$
\Phi_{X}=\left(\begin{array}{cccccccc}
C / G & G & -C / E & -E & 0 & 0 & 0 & 0 \\
C / G & G & 0 & 0 & -C / P & -P & 0 & 0 \\
1 & 0 & 0 & 0 & -G / P & 0 & -P & 0 \\
-E / G & 0 & 1 & 0 & 0 & 0 & 0 & -G
\end{array}\right)^{T}
$$

According to the basic principle of the GDIM model, the variation in carbon emissions $\Delta C$ can be expressed as the sum of the contribution of each factor according to Equation (11):

$$
\Delta C\langle X \mid \Phi\rangle=\int_{L} \nabla C^{T}\left(\mathrm{I}-\Phi_{X} \Phi_{X}^{+}\right) d X
$$

In Equation (11), $L$ is the time span, $\nabla C=\left(\begin{array}{clllllll}C / G & G & 0 & 0 & 0 & 0 & 0 & 0\end{array}\right)^{T}, I$ is its unit matrix, and " + " is the generalized matrix. When the columns of the matrix $\Phi_{X}$ are linearly independent, $\Phi_{X}^{+}=\left(\Phi_{X}^{T} \Phi_{X}\right)^{-1} \Phi_{X}^{T}$.

This paper divides the influencing factors of carbon emissions into three absolute amount factors and into five relative amount factors. The absolute factors include factors that reflect effects of changes in output scale on carbon emissions $\Delta G$, factors that reflect effects of changes in energy consumption scales on carbon emissions $\Delta E$, and factors that reflect effects of changes in population size on carbon emissions $\Delta P$. The relative quantity factor includes factor $\Delta C / G$, which reflects the low-carbon degree of the power industry, and namely a change in the carbon productivity of carbon emissions to reflect the energy use and substitution degree of the power industry. The influence of the energy structure changes on carbon emissions $\triangle C / E$ reflects the effect of changes in carbon emissions per capita on carbon emissions $\triangle C / P$. The effect of changes in per capita GDP on carbon emissions is denoted as $\Delta G / P$, and the extent to which energy production is dependent on energy use in the power sector and the impacts of its use efficiency on carbon emissions are denoted as $\Delta E / G$.

This paper presents a factor analysis of carbon emissions by the power industry for 2000-2015 as a sample interval. The added value of the power industry and the total population were derived from the "China Statistical Yearbook" (2001-2016) [47], and the total energy consumption levels for the power industry were derived from the "China Energy Statistical Yearbook" (2001-2016) [46]. To eliminate effects of price factors on the variables and to ensure the comparability of data, the paper deducts the added value of the power industry for 2000 to a constant price.

\subsection{Scenario Forecast Model Construction and Scenario Setting for Carbon Emissions by the Power Industry}

The following factor analysis shows that in the evolution of carbon emissions by the power industry, the most important growth-inducing factor is the output scale. Carbon intensity of energy consumption and energy intensity can effectively reduce carbon emissions by the power industry and in the future, the power industry should focus on these two aspects when formulating carbon emission reduction policies. To further our scenario analysis, we construct Equation (12):

$$
C=G * \frac{E}{G} * \frac{C}{E}
$$

Suppose that the rate of the change in carbon emissions $(C)$, output scale $(G)$, energy intensity level $(E / G)$, and energy consumption carbon intensity level $(C / E)$ are, respectively, written as $c, a, d$, and $e$ in Equation (13):

$$
\begin{gathered}
C_{t+1}=G_{t+1} \times\left(\frac{E}{G}\right)_{t+1} \times\left(\frac{C}{E}\right)_{t+1} \\
=G_{t} \times(1+a) \times\left(\frac{E}{G}\right)_{t} \times(1+d) \times\left(\frac{C}{E}\right)_{t} \times(1+e)
\end{gathered}
$$

Therefore, the rate of change in carbon emissions $(C)$ is given by Equation (14): 


$$
c=(1+a) \times(1+d) \times(1+e)-1
$$

The evolution of carbon emissions in the power industry is closely related to the evolution trend of the output scale, energy intensity, and energy consumption carbon intensity. To predict future carbon emissions by the power industry, this paper sets the three following future scenarios according to the changing trends and development potentials of various factors for before 2015 and of various emission-reduction policies: The baseline scenario, low-carbon scenario, and technical breakthrough scenario.

(1) Baseline scenario: In this scenario, the power industry develops from the inertia of past development trends. Current economic development, policies, and measures related to carbon emission reduction and technological levels will not change. Economic changes are generally more dependent on inertia. The farther along the cycle is, the lesser its impact on the future will be. The closer a cycle is, the stronger its influence on the future will be [48]. Therefore, taking the annual average rate of the change in potential factors for the recent time frame as a reference, we took the annual average rate of change for each potential factor for 2010-2015 as the intermediate value of the factor for the baseline scenario (i.e., the most likely value). According to Lin and Liu [49], set the changes of various factors, the change range of the potential change rate of the energy intensity index is $0.3-0.5 \%$, and $0.3 \%$ was used in this article. From the potential rate of change in the energy consumption carbon intensity change rate of $0.2 \%$, combined with actual trends for the power industry, we applied a unified $0.15 \%$. The rate of change in the output scale refers to the rate of change in economic growth by $1 \%$. The average annual rate of change in each factor for the baseline scenario is shown in Table 3.

Table 3. Annual average rate of change in each factor for the baseline scenario. Unit: \%.

\begin{tabular}{cccc}
\hline \multirow{2}{*}{ Factor } & \multicolumn{3}{c}{ 2017-2030 } \\
\cline { 2 - 4 } & Min & Med & Max \\
\hline$G$ & 7.69 & 8.69 & 9.69 \\
$E / G$ & -4.62 & -4.32 & -4.02 \\
$C / E$ & -2.02 & -1.87 & -1.72 \\
\hline
\end{tabular}

(2) Low carbon scenario: Under this scenario, the government intensifies its efforts to optimize the energy consumption structure, to improve energy efficiency levels, and begin to enter the green development road. The World Bank expects the average GDP growth rate of 2017-2020 to be $6.27 \%$ [50], which was used as the median of the average annual variability of the output scale in this period under low carbon scenarios. A new economic report on China forecasts that China's GDP will grow at an average yearly rate of 3.28\% from 2020 to 2030 [51]. Morgan Stanley predicts that China's real GDP will grow by $4.6 \%$ each year from 2021 to 2025 [52]. Mr. Teng notes that low carbon targets will have a negative impact on GDP of 1\% [53]. Therefore, average annual change rates for the output scales of 2021-2025 and 2026-2030 were set at 3.6\% and 2.95\%, respectively. The "Strategy for Energy Production and Consumption Revolution" [9] (hereinafter referred to as the "Strategy") proposes that by 2020 , energy consumption levels per unit of GDP will drop by $15 \%$ from 2015 , and thus calculate the potential annual average change rate of energy intensity for 2017-2020 as $-3.2 \%$. According to the "China and New Economic Report," the annual average rate of change in energy intensity levels for 2020 to 2030 under an accelerated emission-reduction scenario is expected to be $2.69 \%$ [51]. With China's increasing levels of investment in renewable energy development under a low-carbon scenario, the potential annual average change rates in energy intensity for 2021-2025 and 2026-2030 were estimated at $-2.51 \%$ and $-2.69 \%$, respectively. Reference the "Strategic Plan of Action for Energy Development" [54], assuming that the proportions of coal, oil, and natural gas consumption in 2020 will, respectively, reach $62 \%, 13 \%$, and $10 \%$, the potential annual average rate of change in energy consumption carbon intensity for $2015-2020$ is expected to be $-2.6 \%$. For the calculation method used, refer to Lin and Liu [49]. The "Strategy" proposes that by 2020-2030, the share of fossil fuels of total 
energy consumption be reduced to $80 \%$, while that for natural gas will decline to $15 \%$ [9]. If uniform changes will occur in proportions of fossil energy and natural gas, coal and oil levels will remain the same with proportions of coal, oil, natural gas consumption in 2025 and 2030 estimated at $58 \%, 12 \%$, and $12 \%$; and $54 \%, 11 \%$, and $15 \%$, respectively. Potential annual rates of change of $-2.72 \%$ and $-2.89 \%$ were, respectively, anticipated for 2021-2025 and 2026-2030. The method of selecting the maximum and minimum values of each factor was in reference to the baseline scenario. The result is shown in Table 4 .

Table 4. Annual rate of change in each factor for the low-carbon scenario. Unit: \%.

\begin{tabular}{ccccccccccc}
\hline \multirow{2}{*}{ Factor } & \multicolumn{3}{c}{ 2017-2020 } & \multicolumn{3}{c}{ 2021-2025 } & \multicolumn{3}{c}{ 2026-2030 } \\
\cline { 2 - 10 } & Min & Med & Max & Min & Med & Max & Min & Med & Max \\
\hline$G$ & 5.27 & 6.27 & 7.27 & 2.6 & 3.6 & 4.6 & 1.95 & 2.95 & 3.95 \\
$E / G$ & -3.5 & -3.2 & -2.9 & -2.8 & -2.5 & -2.2 & -2.99 & -2.89 & -2.39 \\
$C / E$ & -2.75 & -2.6 & -2.45 & -2.87 & -2.72 & -2.57 & -3.04 & -2.89 & -2.74 \\
\hline
\end{tabular}

(3) Technical breakthrough scenario: Under this scenario, assuming that the average annual growth rate of output for all stages is in line with the low-carbon scenario, the power sector has intensified its research and development and investments in energy-saving and emission-reduction technologies to further promote carbon emissions reduction in the power industry. With the development of technologies, energy consumption carbon intensity levels will decline. In considering the time lag of technological breakthroughs, we set an annual average rate of change in energy consumption for 2017-2020 that is in line with the low-carbon scenario. From 2021, the optimization effect of technological breakthroughs will gradually emerge. Therefore, for energy consumption carbon intensity in 2021-2025 and 2026-2030, the average annual change rate of relatively low carbon scenario was decreased by $0.2 \%$. In 2017, the goal set out in the government's "Strategy" is to reduce energy intensity by $15 \%$ in 2020 , compared with 2015 [9], assuming that energy intensity can continue to fall by as much as 15 percent in the event of a breakthrough in energy efficiency technologies. The potential annual change rate in energy intensity for 2017-2020, 2021-2025, and 2026-2030 was calculated to be $-3.2 \%$. The method of selecting the maximum and minimum values of each factor was in reference to the baseline scenario. Results are shown in Table 5.

Table 5. Average annual rate of change in each factor under the technological breakthrough scenario. Unit: \%.

\begin{tabular}{ccccccccccc}
\hline \multirow{2}{*}{ Factor } & \multicolumn{3}{c}{ 2017-2020 } & \multicolumn{3}{c}{ 2021-2025 } & \multicolumn{3}{c}{ 2026-2030 } \\
\cline { 2 - 10 } & Min & Med & Max & Min & Med & Max & Min & Med & Max \\
\hline$G$ & 5.27 & 6.27 & 7.27 & 2.6 & 3.6 & 4.6 & 1.95 & 2.95 & 3.95 \\
$E / G$ & -3.5 & -3.2 & -2.9 & -3.5 & -3.2 & -2.9 & -3.5 & -3.2 & -2.9 \\
$C / E$ & -2.75 & -2.6 & -2.45 & -3.07 & -2.92 & -2.77 & -3.24 & -3.09 & -2.94 \\
\hline
\end{tabular}

\subsection{Summary of the Research Methods}

A summary of the research methods used for the decomposition and scenario prediction of carbon emissions for China's power industry is summarized in Figure 1. 


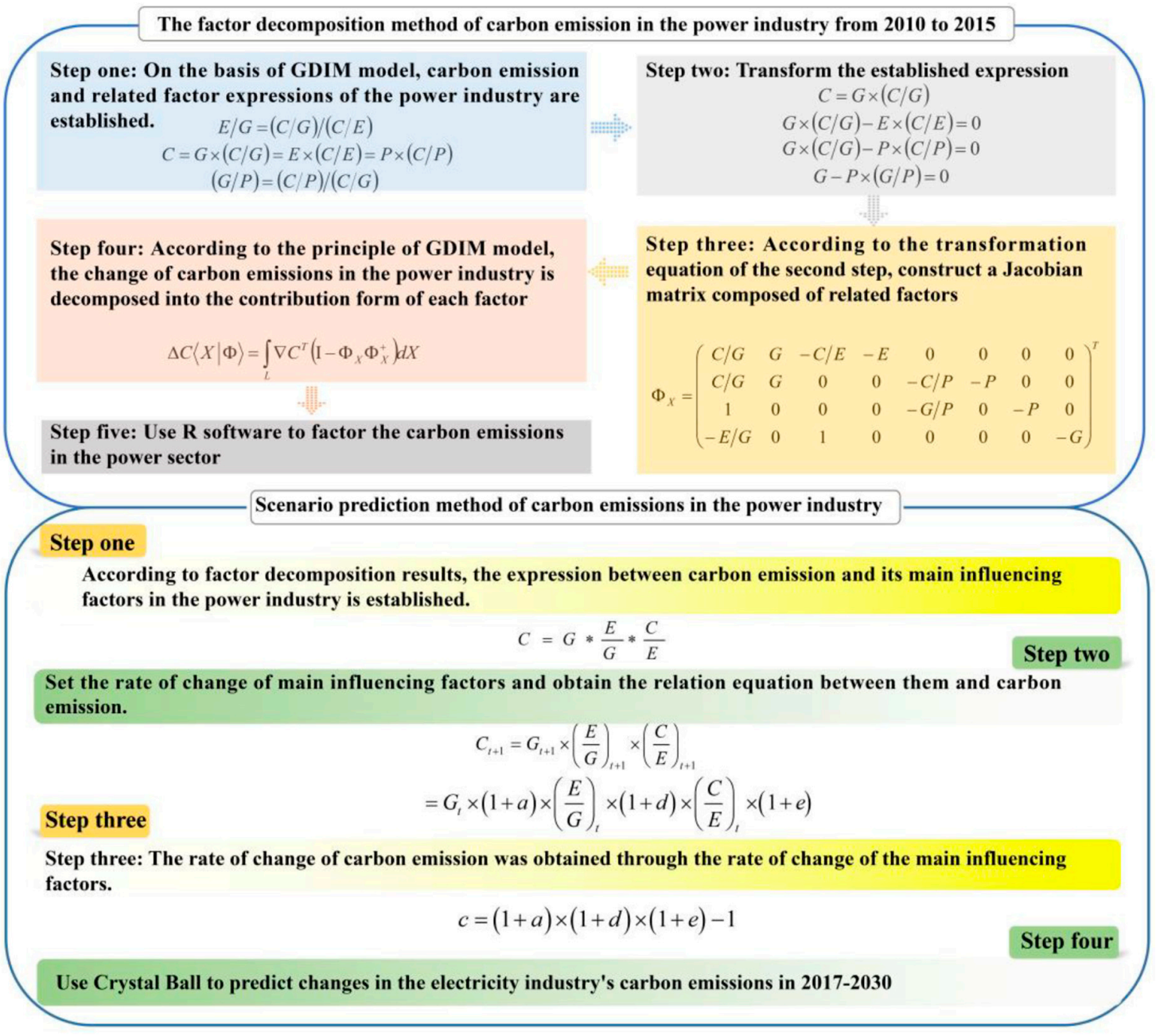

Figure 1. The summary of research methods and models.

\section{Result Analysis}

\subsection{Result Analysis of the Factor Decomposition of Carbon Emissions by the Power Industry}

In this paper, the period of 2000-2015 was divided into three stages: 2000-2005, 2005-2010, and 2010-2015. According to Equations (7) and (11), using R software (Version 3.4.1, MathSoft), the GDIM decomposition of the drivers of carbon emissions from the power sector for each time segment is shown in Figure 2. Figure 2 shows that from 2000 to 2015, the output scale, energy consumption scale, population size, and per capita carbon emissions are major growth factors of carbon emissions in the power industry, while per capita GDP and energy intensity have a restraining effect on the growth of carbon emissions by the power industry. Output carbon intensity and energy consumption carbon intensity have a two-way change in the role of carbon emissions in the power industry.

(1) From 2000 to 2015, output scale, energy consumption scale, population size, and per capita carbon emissions always increased the carbon emissions in the power industry. Of factors that contribute to this increase, the growth effects of the output scale first weakened and then enhanced in three time periods, and was the most significant contributor to increases in carbon emissions observed in 2000-2005 and 2010-2015, causing carbon emissions to reach 360 million tons and 483 million tons, respectively. The growth effect of the output scale for 2005-2010 declined relative to those of the other two time periods, but the contribution of the output scale to the increase in carbon emissions was still significant relative to the other factors. Enhancing effects of the energy consumption scale contrasted 
with those of the output scale, showing slight fluctuations that first increased and then decreased the scale of energy consumption. This generates a maximum volume of 251 million tons of carbon emissions for 2005-2010. Levels were then reduced to 197 million tons in 2010-2015 because for its "The Twelfth Five-Year Plan" period, the Chinese government proposed a national energy development approach to accelerating energy development and to rationally controlling energy consumption. At the same time, the Electricity Industry Federation proposed its "The Twelfth Five-Year Plan" for power generation, which led to a decrease in the scale of energy consumption and of corresponding carbon emissions by the power industry. The growth effect of population size on carbon emissions by the power industry was minor compared to those of the above two factors, but it has been on the rise. Effects of population size on carbon emissions gradually grew more pronounced, rising from 14 million tons for 2000-2005 to 23 million tons for 2010-2015, and was mainly due to changes in the size of Chinese households and due to urbanization. According to census results for 2000 and 2010, family size decreased from 3.44 persons/household to 3.1 persons/household [55], which has led to an increase in the use of household appliances and thus in carbon emissions use in the electricity sector. In the meantime, rates of urbanization in China have increased at an average annual rate of $1.35 \%$ from $36.22 \%$ in 2000 to $56.1 \%$ in 2015 [47]. Compared with rural areas, the perfect level of urban power facilities makes urban residents' electricity consumption more convenient. The increasing effect of carbon emissions per capita on carbon emissions showed a continuing downward trend, from 352 million tons in 2000-2005 to 89 million tons in 2010-2015; this was because the Chinese government set low-carbon targets in its "The Twelfth Five-Year Plan" for 2011. The low-carbon concept was deeply rooted in people's minds, leading to a significant decline in the contribution of per capita carbon emissions to the carbon emissions from the power industry.

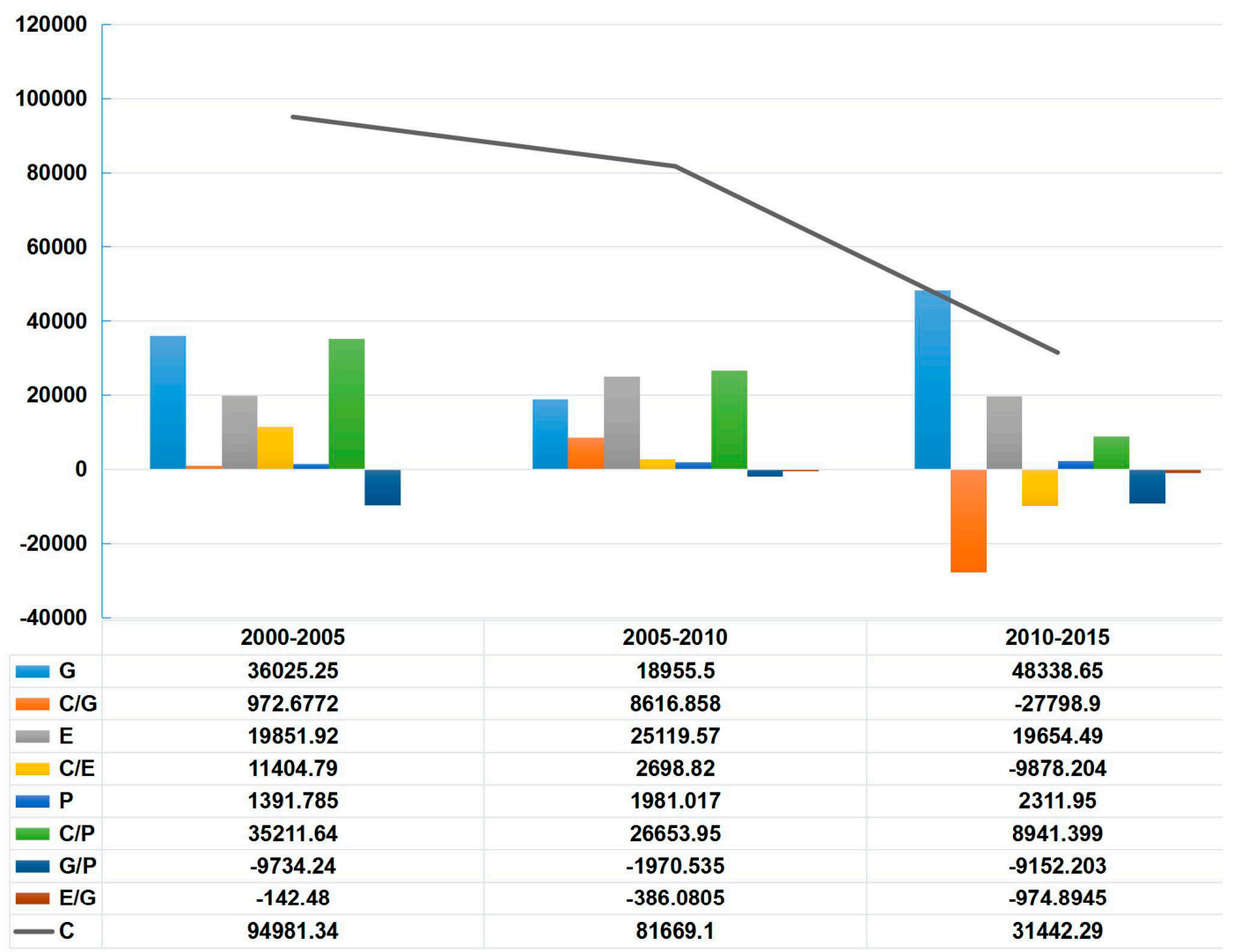

Figure 2. Stages of the decomposition of carbon emissions in the electricity industry. Unit: $10^{4}$ tons.

(2) From 2000 to 2015, energy intensity and per capita GDP have always played a catalytic role in reducing carbon emissions by the power industry. Among them, the declining effect of energy 
intensity on carbon emissions, although relatively weak, showed a trend of continuous increase from 1.4 million tons for 2000-2005 to 10 million tons for 2010-2015. This phenomenon could be attributed to the fact that for the first time, in China's "The Eleventh Five-Year Plan," the energy intensity constraint indicator had been clearly set forth, and targets of a $20 \%$ and $16 \%$ reduction in energy intensity were proposed in the "The Eleventh Five-Year Plan" and "The Twelfth Five-Year Plan" periods, respectively [56]. In addition, "The Thirteenth Five-Year Plan for Energy Development" [8] proposed that energy intensity levels in "The Thirteenth Five-Year Plan" period should drop by more than $15 \%$. Therefore, it is expected that a reduction in energy intensity will continue to promote carbon emissions reduction in the power sector in the coming period. Per capita GDP has always had a catalytic effect on carbon emissions. This appears to be an unreasonable phenomenon that must be clarified. Relative indicators of GDP per capita explicitly include two quantitative indicators (GDP and population), which have a significant impact on carbon dioxide emissions. Changes in these indicators affect their carbonization and are also energy related. As per capita GDP correlates with several indicators, changes in these indicators are affected by calculations of the GDIM model such that changes in per capita GDP are assigned to all these indicators. Only part of the change in these indicators is attributable to per capita GDP, and it is calculated as the effect of changes in carbon dioxide emissions while others are included in the impacts of additional indicators. The results show that the nature of this interconnection had a negative impact on carbon dioxide emissions even when GDP per capita was increasing. In addition, from an environmental point of view, the negative impact of per capita GDP on carbon emissions is also desirable, indicating that the dynamic of population welfare lags behind the gross domestic product [57].

(3) From 2000 to 2015 the carbon intensity of output and the carbon intensity of energy consumption had a two-way effect on carbon emissions by the power industry. Output carbon intensity in 2000-2005 and 2005-2010 contributed to increased carbon emissions in the power industry, and the resulting carbon emissions were 10 million tons and 80 million tons, respectively. The carbon intensity of output had an inhibiting effect on carbon emissions by the power industry for 2010 to 2015, reaching 278 million tons, thus rendering it the most significant contributor to curbing carbon emissions in 2010-2015. This is attributable to new progress made in the reform and development of the power sector from 2010-2015, to structural readjustments, and to remarkable improvements made in technological innovation [58]. As a result, carbon productivity was effectively enhanced (i.e., output carbon intensity was significantly reduced) and carbon emissions dropped significantly. The carbon-strengthening effect of energy consumption carbon intensity continued to decline in 2000-2010. From 2010 to 2015, energy consumption carbon intensity played a catalytic role in reducing carbon emissions by the power industry and reached 100 million tons. This shows that in the "The Twelfth Five-Year Plan" period, energy consumption structures underwent limited carbon transformation. By the end of 2015, non-fossil energy power generation installed capacities accounted for $35 \%$, representing an increase of $8.1 \%$ from 2010 levels, and thermal power installed capacity levels decreased by roughly $9 \%$ from 2010 levels [59]. This shows that the declining carbon intensity of energy consumption will make an important contribution to carbon emission reduction in the power industry.

To more clearly reflect the dynamic impacts of various factors on carbon emissions for 2000 to 2015 , this article took 2000 years as the base period, and obtaining accumulate the contribution value of each factor in the power industry each year, as shown in Figure 3. Figure 3 shows that carbon emissions by the power industry from 2000 to 2013 continuously increased, reaching a maximum level of 2.533 billion tons in 2013-2015, with a downward trend in 2013-2015, and showing a cumulative increase in carbon emissions of 2.081 billion tons in 2015. After 2013, the power industry's decline in carbon emissions has a realistic background. In 2013, the Shenzhen carbon emission trading market, a national carbon trading pilot project, was launched. Subsequently, carbon emissions exchanges, such as those in Beijing, Shanghai, and Tianjin, were successively established, playing an important role in promoting a reduction in carbon emissions. Since the establishment of the four pilot exchanges, enterprises involved in the transactions have mainly focused on the electric power, 
steel, and chemical industries, and more enterprises have started to participate [60]. In December 2017, the government led the power industry through a breakthrough in carbon market construction and launched a nationwide carbon trading system for the power industry, highlighting the importance of reducing carbon emissions by the power industry.

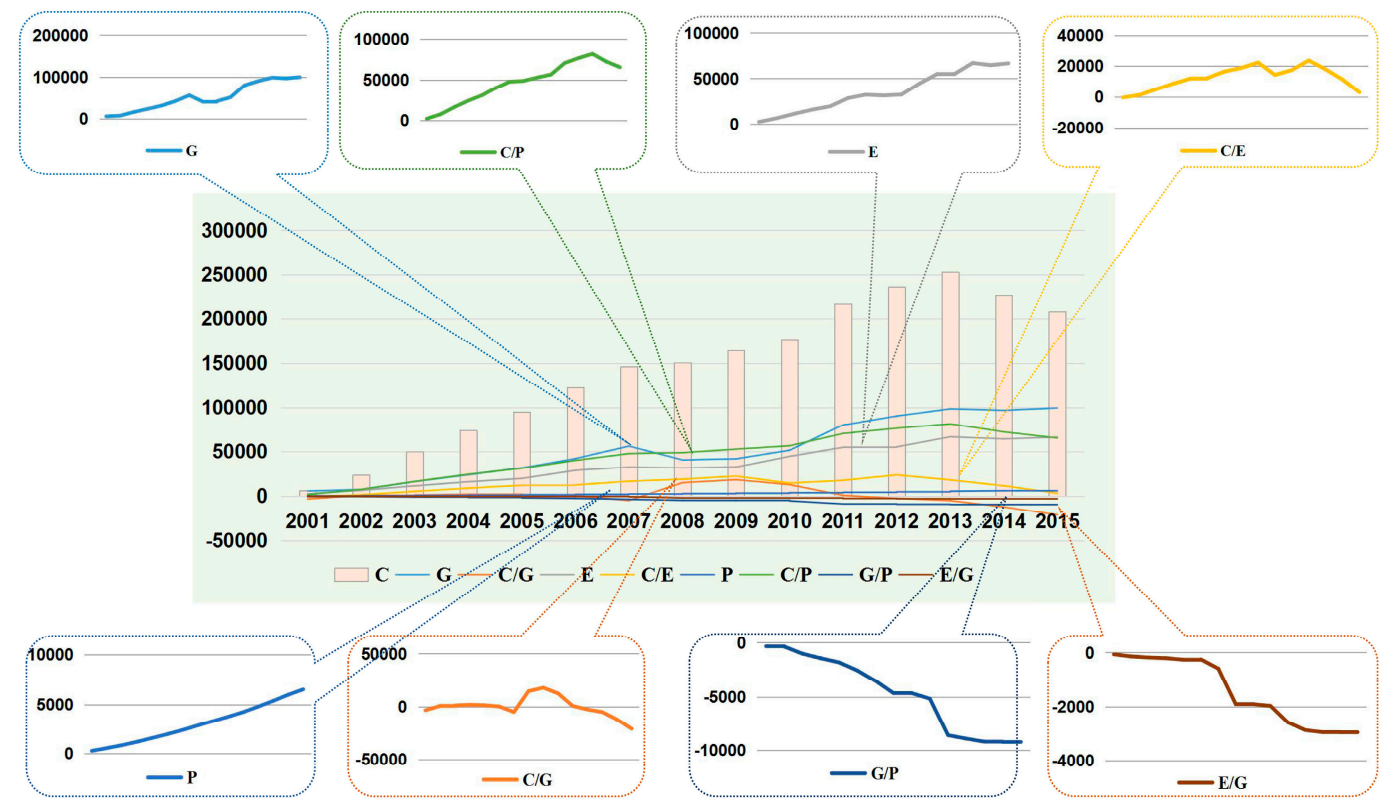

Figure 3. Cumulative contributions of various facets of the power industry to changes in carbon emissions. Unit: $10^{4}$ tons.

As can be observed from Figure 3, carbon emissions generated by the output scale in the power industry increased from 57 million tons in 2001 to 997 million tons in 2015, representing an average annual growth rate of $22.7 \%$. The cumulative increase in carbon emissions generated by per capita carbon emissions in 2001-2013 continued to increase from 2013 to 2015 and gradually decreased from 2000 to 2015 to a cumulative increase of 650 million tons of carbon emissions, representing an average annual growth rate of $28.8 \%$. The cumulative increase in carbon emissions resulting from the scale of energy consumption continued to grow, and relatively was stable in 2013-2015. From 2000 to 2015, the average annual growth rate reached $26.9 \%$ with a cumulative increase of 664 million tons of carbon emissions. The cumulative increase in population size and energy consumption carbon intensity from 2000 to 2015 (with less carbon emissions) reached 65 and 31 million tons, respectively. Emissions resulting from energy intensity and GDP per capita were reduced. Among them, the cumulative increase in carbon emissions resulting from energy intensity decreased rapidly at an annual average rate of $31.4 \%$ from 2000 to 2015, representing a cumulative reduction of carbon emissions of 29 million tons. Carbon emissions generated by per capita GDP in aggregate declined by 92 million tons from 2000 to 2015. The cumulative increase in carbon emissions resulting from the output intensity of carbon continued to increase from 2001 to 2009, reaching a maximum value of 182 million tons in 2009, and the cumulative increase in 2012 turned negative while a cumulative reduction of 209 million tons of carbon emissions occurred in 2000-2015.

The above results show that China has put forward relevant proposals for energy development and that a series of policies and measures aimed at achieving carbon emissions reduction has achieved some success. However, relative to projections, there is still much room for improvement in the realm of power industry carbon reduction. At this stage, China is still a developing country. The overall goal of the development plans is thus to form a developed society. China plans to eliminate absolute poverty through its "The Thirteenth Five-Year Plan" and to achieve economic growth necessary to support a developed society. Thus, the strategy developed to reduce carbon emissions by slowing the 
rate of economic growth is not suited to China's current development plans. In the future, China's power industry should reduce carbon emissions by optimizing energy consumption structures, by increasing levels of clean energy use, by enhancing technologies to improve energy efficiency levels, by increasing investment in energy-saving emissions reduction equipment, and by investing other areas that support the realization of future goals.

In summary, the output scale was the most important factor to promote the carbon emissions in China's power industry, followed by population size and energy consumption scale; energy intensity had a positive effect on carbon emissions reduction in the power industry; and output carbon intensity and energy consumption carbon intensity had a two-way effect on carbon emissions reduction in the power industry.

\subsection{Dynamic Predictions of the Evolution of Future Carbon Emissions by the Power Industry}

Because of the uncertainty of the future development trend and the average annual change rate of the factors affecting the carbon emissions, it can be regarded as the risk variable at the same time, and the carbon emissions are forecasted using a Monte Carlo simulation [29,61,62]. At present, academia has done a lot of meaningful and referential work on the Monte Carlo method [63-66]. The advantage of this method in predicting carbon emissions lies in the assumption of possible values, rather than fixed amplitude changes, based on the relevant literature and research on the future trend of influencing factors, and the probability distributions of different evolution paths of carbon emission are given to identify the most probable evolution paths [49,67].

Based on the above listed annual average rates of change for each factor under different scenarios, we used Monte Carlo simulations to obtain the potential annual average rate of change in carbon emissions in combination with Equation (14) to predict carbon emissions by the power industry for 2017-2030. Given the need to assign a value range to model variables in Monte Carlo simulations, the annual average rate of change for each factor was taken as a variable. The median values of each variable in different time periods under the baseline scenario, low carbon scenario, and technology breakthrough scenario were taken as the minimum, median, and maximal values of the variable in the corresponding scenario in 2017-2030. Corresponding results are shown in Figure 4.

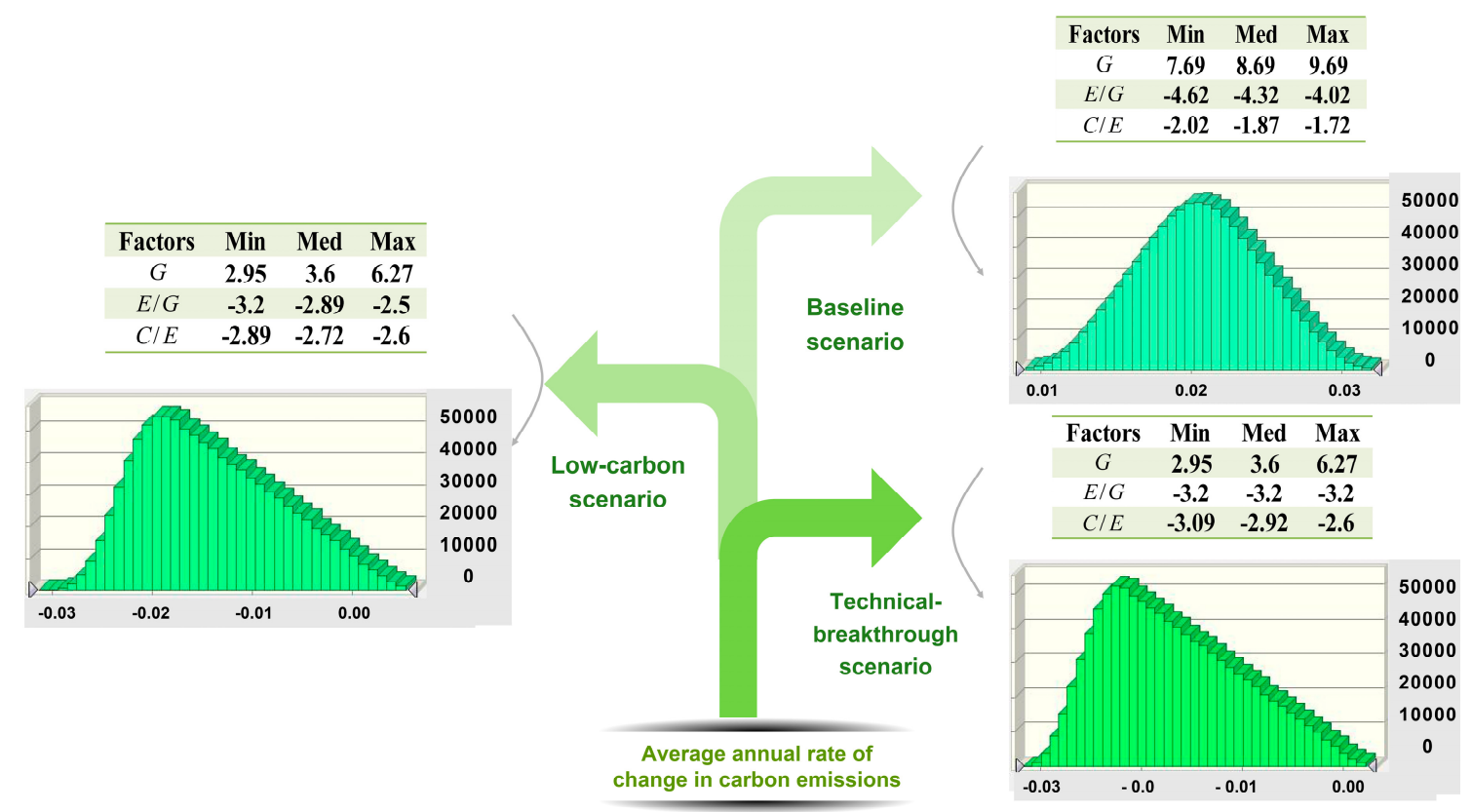

Figure 4. Average annual rate of change in carbon emissions by the power industry for different scenarios of 2017 to 2030. 
The distribution of triangles is most suited for the random selection of variables when the most probable result of known variables and the interval of values are known but when the shape of the probability distribution is unknown [68]. The most likely result of each variable in this article is the middle value. We use the triangle distribution as minimum, median, and maximum values to establish the relationship between the probability distribution, and then the simulation variable value is arbitrarily selected from a random range, which is more realistic. We used the Crystal Ball tool to simulate the average annual rate of change in carbon emissions by the power industry for three scenarios through 1 million simulations, the results of which are shown in Figure 4.

Figure 4 shows all the scenarios based on the assumption that the potential average annual growth rate in carbon emissions generated by the power sector from 2017 to 2030 is likely to be high. The figure shows the following:

1. Under the baseline scenario, the average yearly growth rate of the maximum probability of carbon emissions in China's power industry for 2017 to 2030 is expected to range between $1.9 \%$ and $2.2 \%$. The forecasted growth rate of carbon emissions under the baseline scenario shows that in the current development of economic and carbon emissions, the power industry is expected to have a rebound in carbon emissions, with an annual growth probability of $1.9-2.2 \%$ in 2017-2030. When calculated according to the minimum rate of increase, carbon emissions generated by the power sector in 2030 are expected to reach 4079.14 million tons under the baseline scenario.

2. Under the low carbon scenario, the average annual growth rate of carbon emissions in China's power industry for 2017 to 2030 is likely to range between $-2.1 \%$ and $-1.6 \%$. Compared to the baseline scenario, carbon emissions will continue to decline in the low-carbon scenario. As the low-carbon scenario was based on a series of related goals set forth by the country's current carbon emissions, this shows that the government's green development plan for the future of the country is expected to have a catalytic effect in reducing carbon emissions generated by the power sector.

3. With regard to technological breakthroughs, the average annual growth rate of the maximum probability in carbon emissions in China's power industry for 2017 to 2030 is expected to range between $-2.4 \%$ and $-1.9 \%$. Compared to those of the baseline and low-carbon scenarios, reductions in carbon emissions achieved under the technology breakthrough scenario are expected to be the greatest. At this time, carbon emissions reduction achieved in the power sector under this scenario are expected to be the best among the three scenarios.

In addition, emissions levels can decline faster or slower under each scenario, though with a low probability. However, low probability events can still occur. From the changes in carbon emissions by the power industry found under the three scenarios, future declines in carbon emissions are predicted to be ordered as follows: baseline scenario < low-carbon scenario < technological breakthrough scenario. If in the low-carbon scenario, the power industry was to actively implement the concept of low-carbon development and adhere to the green development path, carbon emissions are predicted to continue to decline. However, over the long term there may not be a significant breakthrough in carbon emissions reduction relative to China's proposed carbon reduction targets. With regard to technological breakthroughs, we predict a breakthrough in technologies of low-carbon energy and energy conversion efficiency, in power generation equipment, and in other realms, and we anticipate significant reductions of carbon emissions accordingly. In summary, according to these predictions, the long-term development of carbon emissions by the power industry should adhere to low-carbon green development while at the same time focusing on low-carbon technological research and development and equipment upgrading, which are expected to make a big contribution to the future development of carbon emissions reduction.

Summarize: Under the baseline scenario, low-carbon scenario, and technological breakthrough scenario, the average annual growth rate of the maximum probability of carbon emissions in China's power industry from 2017 to 2030 are expected to be: [1.9\%, 2.2\%], [-2.1\%, $-1.6 \%]$, and [ $-2.4 \%,-1.9 \%]$. 


\section{Discussion and Analysis}

\subsection{The Results of This Paper Are Compared to Those of Previous Studies}

Wang et al. [69] and Hou et al. [55] studied the carbon emissions of the power industry in the same way, but the method used was different from this article. Therefore, this article selects the two studies and compares these results with the results of this study. The common factors that Wang and this paper chose are economic scale, population size, and energy structures; the common factors that Hou and this paper chose are population size and energy structures. From the common factors shaping carbon emissions by the power industry, the results are shown in Table 6.

Table 6. Contributions of each common factor shaping carbon emissions by the power industry. Unit: \%.

\begin{tabular}{cccc}
\hline Common Factor & Wang et al. & Hou et al. & This Paper \\
\hline Contribution of economic scale & 109.51 & & 102.7 \\
Contribution of population size & 7.92 & 8.1 & 3.03 \\
Contribution of energy structures & 0.51 & 3.9 & 7.8 \\
\hline
\end{tabular}

As is shown in Table 6, although the influence factors selected by the representative literature overlap with this article, the contributions of the measured variables to carbon emissions by the power industry vary. At an economic scale, contribution shown in the compared literature are slightly greater than those shown in this paper and mainly because the LMDI model used in the representative literature for factorization can present slightly higher economic impacts on carbon emissions. For population size, contributions presented in the compared literature are greater than those shown in this article. At present, China's population growth rate is declining, and awareness of issues of energy conservation and environmental protection among residents is on the rise. Contributions of population size to carbon emissions by the power industry should thus be relatively low. For energy structures, the results of the contribution is $7.8 \%$ in this paper while the compared studies present values of $0.51 \%$ and $3.9 \%$. Although the optimization of energy structures will significantly decrease carbon emissions by the power industry, several technical problems related to the development and application of clean energy must still be resolved, and while energy structure optimization has achieved success in recent years, challenges remain. Therefore, the past optimization of energy structures has made strong contributions to the reduction of carbon emissions by the power industry.

\subsection{The Significance of Research Results Presented in This Paper}

This paper presents main factors that shape carbon emissions generated by the power industry. Future changes in carbon emissions generated from this industry are predicted to help governments and related enterprises take measures to reduce carbon emissions while seizing opportunities and fully tapping into potential for carbon emissions reduction based on the influencing factors identified. At the same time, future plans can be made based on the predicted changes in future carbon emissions, thus contributing to the overall energy conservation and emissions reduction efforts. In this paper, the research ideas and methods of carbon emissions in the power industry have some reference value to the research of carbon emissions in other industries.

\subsection{Study Limitations and Avenues for Future Research}

This paper does not consider impacts of electricity consumption in the study of carbon emissions by the power industry. The research content related to the power industry is very extensive. For example, J.H. Huh et al. discussed the hybrid advanced metering infrastructure design for a micro grid based on the game theory model [70], which is a low-reliability problem of the power line communication (PLC) caused by the signal interference and attenuation, and the solution to 
the method was described in the results of the test bench experiment [71] and smart grid test bed that used OPNET software (14.5, OPNET Technologies, Inc., Washington, DC, USA) and power line communication [72]. The study of carbon emissions in the power industry is also very extensive. This paper involves the factor decomposition of carbon emissions in the power industry and sets relevant scenarios for prediction. There are other aspects of carbon emissions in the power industry that can be further studied. Future research can be carried out in the following aspects:

1. Future research can estimate the responsibility for carbon emissions in the provincial power industry, and synthetically consider the responsibilities of producers and consumers. It is beneficial for all regions to undertake the responsibility of carbon emissions reduction fairly and achieve coordinated emissions reduction in all regions.

2. Track and analyze the carbon intensity of demand-side power such that users can understand their carbon emissions responsibility and increase the enthusiasm of users for clean energy consumption.

3. For the generator sets with different carbon emission factors, study the unit's power generation, market electricity price, and carbon emissions, and establishing a carbon emission right allocation mechanism with strong emissions reduction incentives.

4. Compare the international carbon emissions trading system with China's carbon emissions trading system, and analyze the shortcomings and advantages of China's carbon emissions trading system compared with other countries. Furthermore, draw lessons from countries and improving China's carbon emissions trading system combined with China's reality.

5. Analyze the impact of the implementation of carbon tax policy on carbon emissions reduction in the power industry, demonstrate the feasibility of incorporating the carbon tax into the future carbon emissions reduction policy, and provide reference for the government to introduce a carbon tax policy.

\section{Main Conclusions and Recommendations}

\subsection{Main Conclusions}

As a major carbon emissions-generating industry in China, the electric power industry is a major target of China's energy conservation and emissions reduction plan. Therefore, it is important to find a suitable path toward carbon emissions reduction in the power industry. First, this paper applies the GDIM model to the electric power industry from 2000-2015 to examine the factors that shape carbon emissions levels. To set the future annual average rate of change of major influencing factors according to government policy objectives, we used the Monte Carlo method to simulate the potential average annual change rate in carbon emissions from 2017 to 2030 for the power industry. The main conclusions of this study are as follows.

1. Under the reality of China's rapid economic development and thermal power generation as the main force, the output scale was the most important factor leading to the increase of carbon emissions in the power industry, and the cumulative increase of carbon emissions in 2000-2015 reached 996.89 million tons. Energy consumption scales and population size were also important factors for the increase of carbon emissions in the power industry, and the cumulative increase of carbon emissions reached 664.340 million tons and 65.204 million tons, respectively. Because fossil energy consumption still accounts for a large proportion in the energy structure of China's power industry, energy intensity and carbon intensity effects of energy consumption have great carbon emission reduction potential. The energy intensity had reduced the carbon emissions by 29.4241 million tons in 2000-2015, and carbon intensity of energy consumption achieved a breakthrough in carbon emissions from positive to negative effects. In the future, the two are expected to become the main factors to promote carbon emission reduction in the power sector. At present, the power industry in China should focus on the optimization of energy structure to further reduce carbon emissions in the power industry.

2. In different scenarios, changes in carbon emissions of the power industry are different from 2017 to 2030. In the baseline scenario, the maximum probability of a potential annual growth rate 
of carbon emissions is expected to be between $1.9 \%$ and $2.2 \%$. Under the low-carbon scenario and technological breakthrough scenario, the maximum probability of the potential annual drop rate of carbon emissions are expected to be between $1.6-2.1 \%$ and $1.9-2.4 \%$, respectively. Thus, in the current state of development, China's power industry carbon emissions will likely continue to increase. If there is a breakthrough in the low carbon policy and energy-saving and emission-reduction technologies, the carbon emissions of the power industry are expected to reduce. Under the technological breakthrough scenario, the power industry is predicted to experience the strongest reduction in carbon emissions and thus, technological breakthroughs are considered to be the main path for future carbon emission reduction development in the power industry.

The summary of the main conclusions in this paper can be seen in Table 7.

\subsection{Recommendations}

1. Promote green economics and reduce total energy consumption. Accelerate the transformation of economic development modes; focus on the quality of economic growth; and gradually adopt new economic models that limit energy consumption, pollution and emissions generation while upgrading industrial structures to change the structure of electricity consumption. In addition, change the traditional method of coal combustion, realize secondary processing of coal, and reduce end-use energy consumption, especially in energy intensive sectors, such as steel manufacturing.

2. Improve public awareness of energy conservation issues and optimize energy consumption structures. Encourage energy conservation policies, formulate relevant energy efficiency standards and norms, enhance public awareness of energy saving and emissions reduction, and reduce electricity consumption. At the same time, limit thermal power production using coal and improve the ratio of natural gas to fossil energy use. To protect the environment, develop solar energy, hydropower, wind energy, and low-carbon energy generation options by encouraging low-carbon energy power generation and reduce carbon emissions by the power industry.

3. Encourage the use of low-carbon equipment and boost technological innovation research and development. At present, the international investment in innovation and research and development continues to increase. In 2017, the European Union issued the third phase of "Horizon 2020" [73], which comprehensively proposed the goals of climate action and sustainable development, and invested 2.205 billion euros to support the research and innovation of energy technology. As the world's largest carbon emitter, China should upgrade energy-saving and emissions-reduction equipment in the power industry, strengthen international exchanges and cooperation in environmental technologies, and increase investment in innovative technologies for emissions reduction on the basis of adhering to a series of low-carbon development measures. At the same time, the government must encourage enterprises to adopt incentives and invest more in continuous research and development in new energy savings and emissions-reducing technologies as well as production equipment. Low-carbon technologies must be developed to realize further reductions in electric carbon emissions by the power industry.

4. Explore the market potential of biomass power generation. Based on Molina's research [74-76], and combined with the current situation of China's agriculture, biomass power generation should be vigorously developed. The utilization of agricultural and forestry wastes by biomass power generation not only eliminates methane emissions from biomass stacking or landfill fermentation, but also promotes the development of carbon emissions reduction in the power industry, which fully embodies the concept of a circular economy. The government should adopt an active incentive mechanism to enhance the enthusiasm and market activity of biomass power generation industry to a greater extent. 
Table 7. Main conclusions of this paper.

\begin{tabular}{|c|c|c|c|c|c|c|c|}
\hline \multirow{3}{*}{ Factor } & \multicolumn{4}{|c|}{$\begin{array}{l}\text { The Contribution of Various Decomposition Factors to the Changes of } \\
\text { Carbon Emissions in China's Power Industry ( } 10^{4} \text { Tons) }\end{array}$} & \multirow{3}{*}{ Effect } & \multirow{3}{*}{ Degree of Influence } & \\
\hline & \multicolumn{3}{|c|}{ Stage Contributions } & \multirow{2}{*}{$\begin{array}{l}\text { Cumulative } \\
\text { Contributions }\end{array}$} & & & \\
\hline & 2000-2005 & $2005-2010$ & 2010-2015 & & & & \\
\hline Output scale & $36,025.25$ & $18,955.5$ & $48,338.65$ & $99,689.402$ & Positive & Biggest & \multirow{8}{*}{ Factor decomposition } \\
\hline Energy consumption scale & $19,851.92$ & $25,119.57$ & $19,654.49$ & $66,434.07$ & Positive & Bigger & \\
\hline Population size & 1391.785 & 1981.017 & 2311.95 & 6524.081 & Positive & Small & \\
\hline Per capita carbon emissions & $35,211.64$ & $26,653.95$ & 8941.399 & $65,413.974$ & Positive & Bigger & \\
\hline Energy intensity & -142.48 & -386.081 & -974.895 & -2942.41 & Negative & Smaller & \\
\hline Carbon intensity of output & 972.6772 & 8616.858 & $-27,798.9$ & $-20,934.45$ & Double-sided & Bigger & \\
\hline Per capita GDP & -9734.24 & -1970.54 & -9152.2 & -9254.794 & Negative & Small & \\
\hline Carbon intensity of energy consumption & $11,404.79$ & 2698.82 & -9878.2 & 3171.344 & Double-sided & Bigger & \\
\hline \multicolumn{7}{|c|}{ Simulation results of the average annual growth rate of carbon emissions in China's power industry under different scenarios from 2017 to 2030} & \\
\hline & \multicolumn{3}{|c|}{ Characteristics of the scenario } & \multicolumn{3}{|c|}{$\begin{array}{l}\text { The most probable value } \\
\end{array}$} & \\
\hline Baseline scenario & \multirow{3}{*}{\multicolumn{3}{|c|}{$\begin{array}{l}\text { According to the current development trend } \\
\text { Follow the path of green development } \\
\text { Strengthen technological R\&D investment }\end{array}$}} & \multirow{3}{*}{\multicolumn{3}{|c|}{$\begin{array}{c}1.9 \% \text { to } 2.2 \% \\
-2.1 \% \text { to }-1.6 \% \\
-2.4 \% \text { to }-1.9 \%\end{array}$}} & \multirow{3}{*}{ Scenario forecasts } \\
\hline Low-carbon scenario & & & & & & & \\
\hline Technical breakthrough scenario & & & & & & & \\
\hline
\end{tabular}


Author Contributions: L.Z. was mainly responsible for the writing of the full text. X.M. conceived and designed the study. L.H., P.S., and Y.Z. built the models of the paper.

Acknowledgments: This paper is supported by Humanities and Social Sciences Research Project of Ministry of Education (18YJC910013), National Natural Science Foundation (71573034), Liaoning Economic and Social Development Research Project (2018lslktzd-010), Liaoning Social Science Fund (L17CTJ001, L17BJY042), China Postdoctoral Science Foundation special fund (2017T100180), China Postdoctoral Science Foundation (2016M601318), and Research Project of Dongbei University of Finance and Economics (DUFE2017Q16), National Social Science Foundation Key Project (17ATJ002), National Statistical Research Projects (2016LY42).

Conflicts of Interest: The authors declare no conflict of interest.

\section{References}

1. Global Warming. Available online: https://www.pishu.cn/psbk/psgd/zyhj/383725.shtml (accessed on 30 August 2018).

2. Ge, Q.S.; Wang, F.; Wang, S.W.; Cheng, B.B. Determination and uncertainty of seven questions about global warming. China Popul. Resour. Environ. 2014, 24, 1-6.

3. Blunden, J.; Arndt, D.S.; Baringer, M.O. State of the Climate in 2010. Bull. Am. Meteorol. Soc. 2011, 92, S1-S236. [CrossRef]

4. $\mathrm{Fu}, \mathrm{Y}$. The causes and effects of global warming. J. Cap. Norm. Univ. 2007, 06, 11-21.

5. Liu, Y.; Zheng, Y.Y.; Ge, Q.S.; Wang, F. China's greenhouse gas emission changes under the background of low carbon development and its contribution to global emission reduction. Resour. Sci. 2017, 39, 2399-2407.

6. Global Carbon Project Releases "Global Carbon Budget 2016", Global Carbon Emissions Increase Continued to Decline for the Third Year. Available online: http:/ / cnc-fe.cast.org.cn/ (accessed on 15 December 2017).

7. "Global Carbon Budget Report": Strong Global Carbon Emissions Rise 2017 | China Meteorological Administration. Available online: http:/ /m.cma.gov.cn/2011xwzx/2011xqhbh/2011xdtxx/201711/t20171122_ 456610.html (accessed on 15 December 2017).

8. Energy Bureau Released “The Eleventh Five-Year Plan" and "The Twelfth Five-Year Plan". Available online: http:/ / www.gov.cn/xinwen/2017-01/05/content_5156795.htm\#1 (accessed on 20 November 2017).

9. Du, X.W. Interpretation and reflection on China's "Strategy of Energy Production and Consumption Revolution (2016-2030)". China Econ. Trade Herit. 2017, 15, 44-45.

10. Zhang, W. Sampling and Separation Performance of Coal Fly Ash in Power Plant. Master's Thesis, Beijing Jiaotong University, Beijing, China, 2010.

11. Yu, Y.H.; Lv, D.W. China's power industry emissions reduction policy-An empirical analysis based on power demand function. Technol. Econ. 2017, 36, 110-118.

12. Cheng, H.Z. China's small hydropower and rural electrification. Small Hydro Power 2001, 17, 1-6.

13. Han, D.; Zhao, Y. Talking about new energy power generation and its development prospects. Tech. Wind 2018, 30, 123.

14. National Energy Administration. Available online: http:/ / www.nea.gov.cn/ (accessed on 30 August 2018).

15. Bhat, I.K.; Prakash, R. LCA of renewable energy for electricity generation systems-A review. Renew. Sustain. Energy Rev. 2009, 13, 1067-1073.

16. Lenzen, M. Life cycle energy and greenhouse gas emissions of nuclear energy: A review. Energy Convers. Manag. 2008, 49, 2178-2199. [CrossRef]

17. Quesada-Rubio, J.M.; Villar-Rubio, E.; Madrid-Salvador, V.; Molina-Moreno, V. The gap between $\mathrm{CO}_{2}$ emissions and allocation rights in the Spanish industry. Environ. Eng. Manag. J. 2010, 9, 1161-1164. [CrossRef]

18. Quesada-Rubio, J.M.; Villar-Rubio, E.; Mondéjar-Jiménez, J.; Molina-Moreno, V. Carbon dioxide emissions vs. allocation rights: Spanish case analysis. Int. J. Environ. Res. 2011, 5, 469-474.

19. Mikayilov, J.I.; Galeotti, M.; Hasanov, F.J. The impact of economic growth on $\mathrm{CO}_{2}$ emissions in Azerbaijan. J. Clean. Prod. 2018, 197, 1558-1572. [CrossRef]

20. Bollen, J.C.; Toet, A.; Vries, H.D. Evaluating cost-effective strategies for meeting regional $\mathrm{CO}_{2}$ targets. Glob. Environ. Chang. 1996, 6, 359-373. [CrossRef]

21. Remuzgo, L.; Sarabia, J.M. International inequality in $\mathrm{CO}_{2}$ emissions: A new factorial decomposition based on Kaya factors. Environ. Sci. Policy 2015, 54, 15-24. [CrossRef]

22. Zhu, Q.; Peng, X.Z.; Lu, Z.M.; Wu, K.Y. Factor decomposition and empirical analysis of China's carbon emissions from energy consumption. Resour. Sci. 2009, 31, 2072-2079. 
23. Xia, C.; Li, Y.; Ye, Y.; Shi, Z.; Liu, J. Decomposed driving factors of carbon emissions and scenario analyses of low-carbon transformation in 2020 and 2030 for Zhejiang province. Energies 2017, 10, 1747. [CrossRef]

24. Kopidou, D.; Diakoulaki, D. Decomposing industrial $\mathrm{CO}_{2}$ emissions of southern European Countries into production- and consumption-based driving factors. J. Clean. Prod. 2017, 112, 4159-4172. [CrossRef]

25. Mahony, T.O. Decomposition of Ireland's carbon emissions from 1990 to 2010: An extended Kaya identity. Energy Policy 2013, 59, 573-581. [CrossRef]

26. Wang, F.; Wu, L.H.; Yang, C. Study on the driving factors of the growth of carbon emissions in China's economic development. J. Econ. Res. 2010, 45, 123-136.

27. Wang, J.S.; He, C.F. Consumption of energy, economic growth and $\mathrm{CO}_{2}$ emissions in China: A decomposition analysis based on LMDI. Resour. Environ. Yangtze Basin 2010, 19, 18-23.

28. Du, L.; Wei, C.; Cai, S. Economic development and carbon dioxide emissions in China: Provincial panel data analysis. China Econ. Rev. 2012, 23, 371-384. [CrossRef]

29. Dong, F.; Yang, Q.L.; Long, R.Y.; Cheng, S.B. Chinese carbon decomposition and dynamic simulation. China Popul. Resour. Environ. 2015, 25, 1-8.

30. Ali, H.; Sanjaya, S.; Suryadi, B.; Weller, S.R. Analysing $\mathrm{CO}_{2}$ emissions from Singapore's electricity generation sector: Strategies for 2020 and beyond. Energy 2017, 124, 553-564. [CrossRef]

31. Sun, W.; Meng, M.; He, Y.; Chang, H. $\mathrm{CO}_{2}$ emissions from china's power industry: Scenarios and policies for 13th five-year plan. Energies 2016, 9, 825. [CrossRef]

32. Wu, Q.; Peng, C. Scenario analysis of carbon emissions of china's electric power industry up to 2030. Energies 2016, 9, 988. [CrossRef]

33. Cai, W.; Wang, C.; Wang, K.; Zhang, Y.; Chen, J. Scenario analysis on $\mathrm{CO}_{2}$ emissions reduction potential in China's electricity sector. Energy Policy 2007, 35, 6445-6456. [CrossRef]

34. Ari, I.; Koksal, M.A. Carbon dioxide emission from the Turkish electricity sector and its mitigation options. Energy Policy 2011, 39, 6120-6135. [CrossRef]

35. Hou, J.C.; Tan, Z.F. Decomposition of influencing factors on $\mathrm{CO}_{2}$ emissions from power production. Electr. Power 2011, 44, 39-42.

36. Steenhof, P.A.; Weber, C.J. An assessment of factors impacting Canada's electricity sector's Ghg emissions. Energy Policy 2011, 39, 4089-4096. [CrossRef]

37. Chen, X.K.; Zhou, T.R.; Li, X.; Kang, C.Q.; Chen, Q.X. Analysis on decomposition of carbon emission structure and contribution to low carbon in power system. Autom. Electr. Power Syst. 2012, 36, 18-25.

38. Huo, M.L.; Han, X.Y.; Shan, B.G. An empirical analysis of the influencing factors of carbon emissions intensity in China's power industry. Electr. Power 2013, 46, 122-126.

39. Shrestha, R.M.; Anandarajah, G.; Liyanage, M.H. Factors affecting $\mathrm{CO}_{2}$ emission from the power sector of selected countries in Asia and the Pacific. Energy Policy 2009, 37, 2375-2384. [CrossRef]

40. Malla, S. $\mathrm{CO}_{2}$ emissions from electricity generation in seven Asia-pacific and North American Countries: A decomposition analysis. Energy Policy 2009, 37, 1-9. [CrossRef]

41. Zhang, N.; Zhou, P.; Choi, Y. Energy efficiency, $\mathrm{CO}_{2}$ emission performance and technology gaps in fossil fuel electricity generation in Korea: A Meta-Frontier Non-Radial Directional Distance Function analysis. Energy Policy 2013, 56, 653-662. [CrossRef]

42. Hu, J.; Kahrl, F.; Yan, Q.; Wang, X. The impact of China's differential electricity pricing policy on power sector $\mathrm{CO}_{2}$ emissions. Energy Policy 2012, 45, 412-419. [CrossRef]

43. Özer, B.; Görgün, E.; İncecik, S. The scenario analysis on $\mathrm{CO}_{2}$ emission mitigation potential in the Turkish electricity sector: 2006-2030. Energy 2013, 49, 395-403. [CrossRef]

44. Liu, Z.; Zhu, K.W.; Yan, J.M.; Shi, Y.R. Design and analysis of carbon emissions reduction scenarios in the power industry. Power Syst. Technol. 2012, 36, 1-7.

45. Intergovernmental Panel on Climate Change (IPCC). 2006 IPCC Guidelines for National Greenhouse Gas Inventories. Available online: https://wenku.baidu.com/view/4eb6dad4195f312b3169a5a9.html (accessed on 8 November 2017).

46. National Bureau of Statistics of People's Republic of China. China Energy Statistical Yearbook. 2016. Available online: http://www.stats.gov.cn/tjsj/tjcbw/201706/t20170621_1505833.html (accessed on 10 November 2017).

47. National Bureau of Statistics of People's Republic of China. China Statistical Yearbook. 2011-2016. Available online: http:/ / www.stats.gov.cn/tjsj/ndsj/ (accessed on 10 November 2017). 
48. Zheng, S.M. Political cycle, five years planning and environmental pollution-Taking industrial sulfur dioxide emission as an example. Cass J. Political Sci. 2016, 2, 80-94.

49. Lin, B.Q.; Liu, X.Y. Carbon emissions in China's urbanization: Influencing factors and emission reduction strategy. Econ. Res. J. 2010, 45, 66-78.

50. IMF World Economic Outlook (WEO) update, January 2017: A Shifting Global Economic Landscape. Available online: http:/ /www.imf.org/external/pubs/ft/weo/2017/update/01/ (accessed on 23 December 2017).

51. Niu, J.M.; Dai, R.F.; Dong, W.J.; Ban, J.H.; Hu, C.Y. China's future $\mathrm{CO}_{2}$ emissions scenarios under the US new deal background climate prediction. Adv. Clim. Chang. Res. 2018, 01, 95-105.

52. Morgan Stanley: Avoid the Banking Crisis, We Are Optimistic about China! Available online: http:/ / oversea. huanqiu.com/article/ (accessed on 25 December 2017).

53. China's Carbon Pricing Is Expected to Reach 10-25 Yuan/Ton in 2020-2030. Available online: http:/ / www. tanpaifang.com/tanqiquan/2014/1115/40146.html (accessed on 26 December 2017).

54. General Office of the State Council of the People's Republic of China issued "Action Plan for Energy Development Strategy (2014-2020)". Constr. Sci. Tech. 2014, 22, 6.

55. Hou, J.C.; Shi, D. Study on the driving factors of carbon emissions changes in China's power industry. China Ind. Econ. 2014, 06, 44-56.

56. People's Republic of China National Economic and Social Development Twelfth Five-Year Plan. People's Daily 2011, 1, 1-56.

57. Vaninsky, A. Factorial decomposition of $\mathrm{CO}_{2}$ emissions: A Generalized Divisia Index Approach. Energy Econ. 2014, 45, 389-400. [CrossRef]

58. China Electricity Council. Condense together the past to create a new brilliant power industry-A Summary of China electricity council service industry development since 2010. China Power Enterp. Manag. 2016, 12-15.

59. China Electricity Council. China's Power Industry Annual Development Report 2016; China Electronic Production Equipment Industry Association: Beijing, China, 2016; pp. 18-23.

60. Zeng, M.; Yao, J.; Zhao, X.L. Effects of carbon emissions trading on the power industry. China Power Enterp. Manag. 2014, 5, 23-26.

61. Lin, B.; Wang, X. Promoting energy conservation in China's Iron \& Steel Sector. Energy 2014, 73, 465-474.

62. Wu, Y.Z.; Shen, J.; Zhang, X. The Impact of urbanization on carbon emissions in developing countries: A Chinese study based on the U-kaya method. J. Clean. Prod. 2016, 135, 589-603. [CrossRef]

63. Salakhutdinov, R.; Mnih, A. Bayesian probabilistic matrix factorization using Markov chain Monte Carlo. In Proceedings of the 25th International Conference on Machine Learning, Helsinki, Finland, 5-9 July 2008; pp. 880-887.

64. Frieze, A.; Kannan, R.; Vempala, S. Fast Monte-Carlo algorithms for finding low-rank approximations. J. ACM 2004, 51, 1025-1041. [CrossRef]

65. Veach, E. Optimally combining sampling techniques for Monte Carlo rendering. In Proceedings of the 22nd Annual Conference on Computer Graphics and Interactive Techniques, Los Angeles, CA, USA, 6-11 August 1995; pp. 419-428.

66. Procopiuc, C.M.; Jones, M.; Agarwal, P.K.; Murali, T.M. A Monte Carlo algorithm for fast projective clustering. In Proceedings of the 2002 ACM SIGMOD International Conference on Management of Data, Madison, WI, USA, 2-6 June 2002; pp. 418-427.

67. Shao, S.; Zhang, X.; Zhao, X.R. Empirical decomposition and peak path of carbon emissions in China's manufacturing industry-Generalized Divisia Index decomposition and dynamic scenario analysis. China Ind. Econ. 2017, 34, 44-63.

68. Ramírez, A.; Keizer, C.D.; Sluijs, J.P.V.D.; Olivier, J.; Brandes, L. Monte Carlo analysis of uncertainties in the netherlands greenhouse gas emission inventory for 1990-2004. Atmos. Environ. 2008, 42, 8263-8272. [CrossRef]

69. Wang, C.K.; Cui, W.J. Construction, intensity, scale and electricity carbon emissions: A study based on LMDI decomposition method. Sci. Technol. Manag. 2015, 35, 220-241.

70. Huh, J.H.; Seo, K. Hybrid advanced metering infrastructure design for micro grid using the game theory model. Int. J. Softw. Eng. Appl. 2015, 9, 257-268. [CrossRef]

71. Huh, J.H.; Otgonchimeg, S.; Seo, K. Advanced metering infrastructure design and test bed experiment using intelligent agents: Focusing on the plc network base technology for smart grid system. J. Supercomput. 2016, 72, 1862-1877. [CrossRef] 
72. Huh, J.H. Smart Grid Test Bed Using OPNET and Power Line Communication. Available online: https:/ / ieeexplore.ieee.org/document/7801748/ (accessed on 5 September 2018).

73. Horizon 2020. Available online: http://ec.europa.eu/programmes/horizon2020/en/area/energy (accessed on 5 September 2018).

74. Molina-Moreno, V.; Núñez-Cacho Utrilla, P.; Cortés-García, F.J.; Peña-García, A. The Use of Led Technology and Biomass to Power Public Lighting in a Local Context: The Case of Baeza (Spain). Energies 2018, 11, 1783. [CrossRef]

75. Nuñez-Cacho, P.; Górecki, J.; Molina-Moreno, V.; Corpas-Iglesias, F.A. What Gets Measured, Gets Done: Development of a Circular Economy Measurement Scale for Building Industry. Sustainability 2018, 10, 2340. [CrossRef]

76. Villar Rubio, E.; Quesada Rubio, J.M.; Molina Moreno, V. Convergence Analysis of Environmental Fiscal Pressure Acrosss EU-15 Countries. Energy Environ. 2015, 26, 789-802. [CrossRef]

(C) 2018 by the authors. Licensee MDPI, Basel, Switzerland. This article is an open access article distributed under the terms and conditions of the Creative Commons Attribution (CC BY) license (http:/ / creativecommons.org/licenses/by/4.0/). 